\title{
Leading and Managing Disparate Generations in Cross-Cultural Learning Organizations
}

Bahaudin Mujtaba, (E-mail: Mujtaba@nova.edu), Nova Southeastern University Gimol Thomas, (E-mail: gthomas@nova.edu), Nova Southeastern University

\begin{abstract}
The enclosed literature focuses on learning about the various generations of the workforce and techniques that employers can utilize to organize collaborative teams in today's multigenerational and multicultural workplaces. Trainers and teachers can use this material to provide effective skills for managers that deal with a multi-generation of employees. Furthermore, educators can use appropriate teaching techniques with different generations of students since teachers of working adults are likely to have diverse generations of learners in their classes. There are at least four different generations in today's workforce that are categorized as traditionalists (Veterans), baby boomers, generation $X$, and generation $Y$ individuals. Managers should be aware of the personality characteristics of individuals in all generations as well as their cultural backgrounds, and act accordingly. The document further discusses how decision-making, for managers of any generation, is a very critical and timeconsuming procedure, and how managerial decisions do affect the company's processes dramatically. Managers should always make certain, regardless of their personal interests, likes and dislikes, that their decisions are appropriate for each generation of employees and their organizations.
\end{abstract}

Organizational learning, from a systems perspective, is discussed as an effective method of understanding the processes and strategies suitable for an organization. In order to create a learning organization, managers need to emphasize teamwork and practice group activities that effectively involve people of all generations in the decision making processes. Following the eight facets of Values Driven Management can guide and focus everyone's energies toward the common vision set forth by the company. Besides dealing with a multi-generation of employees, international managers face an even more complex task since they also deal with various cultures. Hence, a multi-cultural manager should acquire appropriate cultural knowledge regarding the local norms, mores and customs to effectively work with individuals of different generations throughout the world.

\section{Systemic Impact of Disparate Generations in a Learning Organization}



he systems thinking, or a holistic, paradigm allows all senses to work synergistically in the creation of a learning environment through their interactions with the external environment. Perhaps the effectiveness of the five senses working together can result in the awakening of the sixth sense due to the ability to see beyond time and space. The twenty first century organization is much more complex and the best way to effectively address this complexity is to see the 
interconnectedness of the parts through the five senses from the detail to general as well as from internal to external variables while predicting the future. Instead of managing through a critical eye or micro managing, managers need to unleash their potential to see other systems beyond their limits to lead disparate generations in the twenty first century workforce. Also, as the organizations become more complex, managers will need to teach employees to think from a holistic and systemic perspective in order to discover new methods of leading the diverse generations. They need to help employees see how their jobs affect the next step in the chain process and how their functions positively impact the environment. The skills and systems thinking process can be learned to support diverse generations. According to Gazzaniga (1988), the human brain and mindset or paradigm can adapt according to the needs of each generation. Capra (1997) stated that the human mind is powerful enough to facilitate the conceptualization of system thinking including chaotic (complexity) theory and non-lineal mathematical models. The twenty first century manager cannot rely just on the past to effectively move forward and lead diverse generations into the future. As effective leaders and intellectuals, these managers should realize that their self-imposed ideologies of reality must evolve with nature, science, and time in order to foster new strategies for leading today's diverse workforce. These managers must learn to embrace the diversity of various generations in the workforce through the creation of a learning environment throughout the organization.

In the twenty first century's fast pace global environment, organizations need to embrace change as a constant motivating force that provides both opportunities as well as challenges. Throughout the past century, many academic and practitioner scholars have contributed to various schools of organizational theory. These learning organizational theories are commonly categorized into different schools of thought including Classical, Human Resources, Neo-Classical, Systems, Agency, Power, and Sense-Making. The major thoughts of organization theory can change over time and through the ages because of new paradigms and new knowledge. As with any discipline that evolves, organizational theory has been built upon the ideas and paradigms that have been in place prior to the discovery of a new paradigm or a new shift in thinking. An understanding of organizational theory should include, but not be limited to, the historical contexts of the discipline, the cultural nuances of the discipline, and the metaphorical background of the discipline that have given precedence to the established body of knowledge. Having a strong foundation of the basics, as well as, the main authors and contributors to the organizational learning literature are critical for twenty first century managers and academic scholars. More importantly, it is imperative that managers study their employees and the impact of having a multi-generation workforce in the organization. The concepts presented in Senge's (1990) book titled "The Fifth Discipline: the Art and Practice of the Learning Organization” assists individuals in overcoming the illusion that the world is created of separate or unrelated forces (p. 3). It is the letting go of such an illusion that makes a learning organization a possibility. Learning organizations, according to Senge, are "organizations where people continually expand their capacity to create the results they truly desire, where new and expansive patterns of thinking are nurtured, where collective aspiration is set free, and where people are continually learning how to learn together.”

Decision making is one of the most interesting and pervasive concepts in all organizations because people of all generations make decisions concerning various concepts such as leadership style, motivation, productivity, conflict management, human resources management, and so on. As a matter-offact, Senge states that the ability to learn faster than one's competitors for making effective decisions might be the only true competitive advantage for twenty first century managers and organizations. One can always think and reflect upon the importance of decision making and the consequences of making both good and bad decisions. One can also evaluate some of the major decisions and think of how leaders could have approached them differently from a holistic perspective. In the past ten years, every twenty first century leader probably has heard of the merger of Hewlett-Packard and Compaq, Microsoft fighting monopoly allegations, many organizations including Levi Strauss shutting down their factories in the United States and moving overseas which has resulted in layoffs, allowing China to join the World Trade 
Organization (WTO) despite its questionable human rights record, sending air power to Afghanistan to assist in the removal of the Taliban from power, and American and British soldiers occupying Iraq while removing Saddam Hussein from government. So, there have been many examples of major decisions made by corporate and world leaders in hopes of either making the society a better place to live or their organizations more competitive in their industries. As can be seen through the media, there have also been crisis in corporate governance due to unethical decisions, short-term focus on quick profits, excessive senior leadership pay, weak vision for direction, corrupt analysts, complacent boards, and questionable accounting practices in some of the largest organizations. With the controversies surrounding Enron, Arthur Andersen, Tyco and a host of other large organizations that have admitted to, at the very least, having used "poor" judgment in managing stocks and acquisitions, the public trust will have to be restored in the credibility of business. In order to remedy such problems in the business environment and improve the level of trust among the stakeholders, perhaps the senior leaders can set the company's moral tone, ban stock sales by directors for the duration of their terms, send some CFOs and CEOs to jail, and a host of other suggestions might be appropriate as well. However, none of these suggestions will be complete when the focus is on short-term profitability with no consideration on how one aspect impacts all the other elements both inside and outside of the organization. The leaders must see the impact of their decision from a system's perspective as they attempt to create a learning organization.

In a learning organization, leaders and managers can increase everyone's ability to make nonprogrammed decisions, those that allow them to adapt, modify, and alter their tasks by creating an effective and inclusive learning environment (Mujtaba \& Mujtaba, 2004). A learning organization is one in which leaders and managers do everything possible to maximize the potential for organizational learning to take place. Organizational learning is the process through which managers seek to improve understanding and meeting employees' desires and their ability to understand and manage the organization (Jones et al, 2003). This type of environment allows a free flow of ideas from decisions to dealing with their consequences and further creativity. Creativity can be defined as the ability of a decision maker to discover original and novel ideas that lead to feasible alternative courses of action. Brainstorming is an idea-generating and a problem-solving technique in which managers meet face-toface to discuss and debate a wide variety of alternatives from which to make a decision (Jones \& George, 2003). Companies such as 3M, Microsoft and Newell Rubbermaid have been well known for their creative cultures. In such organizational cultures, generally one person describes the problem in broad outline. Then, group members share their ideas and generate courses of action without criticizing each alternative until all suggestions have been heard. Then, group members are encouraged to be innovative and "piggy back" on the ideas they have heard. When all alternatives have been generated, the group members debate the pros and cons and develop a list of the best alternatives. In order to create a learning organization, senior leaders and managers must integrate such creativity and brainstorming in the organization and allow every person in the organization to develop a sense of personal mastery (Senge, 1990). Senge goes on to say that such organizations also need to encourage employees of all generations to develop and use complex mental models. Leaders and managers must do everything they can to promote group creativity and team learning. Leaders and managers must emphasize the importance of building a shared vision. Managers must model and encourage systems thinking because building a learning organization requires leaders and managers to radically change their assumptions. Incorporating systems thinking into the organizational structure provides a vehicle to effectively deal with change at the planning phase as well as the problem analysis phase. The "systems thinking" paradigm provides an avenue for organizations to continuously improve their processes and embrace change using new perspectives and new methods of thinking. Today's organizations can no longer operate in silos or closed systems and expect to be competitive with other national or international firms that effectively operate using all of the resources available to them in the open environment. As such, these organizations must embrace change as well as new ways of seeing and doing things as per a systems thinking mentality. Systems thinking is basically a multidiscipline approach that involves the wholeness of an organization. 
While basic analysis through any means can result in knowledge, systems thinking results in understanding as well as lasting changes. In the application of systems thinking, the entire organization and its subsystems can be investigated to understand each segment of the operation. Understanding the interdependence and interconnections of systems in operation and employees can provide a more holistic environment that embraces change. "Systems thinking" is basically a method of analyzing organizational problems of modern technology, society and organizations from a new weltanschauung, or a new perspective.

Organizations come in all sizes and as such they have differing but distinctive boundaries, rules, roles, communication channels, and views of authority and human stature based on their culture. Consequently there is a high degree of fit between organizational models (metaphors) and how they operate. To some degree all organizational leaders use their mental models in seeking to achieve the goals of the organization, albeit in many cases with externalities or social consequences that impact the effectiveness and productivity of the organization. Most organizational leaders understand that their firms need to stay efficient, effective and sensitive to their environments in order to remain successful and socially responsible. This applies equally to both for-profit and non-for-profit organizations. The degree to which an organization is described as bureaucratic is probably directly correlated to the degree to which it is "unfit for future action." Contributing to fitness for future action is the need for organizational leaders to keep their members aware and focused on the collective vision of the organization in order to attain the unity of action required for success. They can best complete this responsibility by clearly communicating this reality and then helping people see and achieve the vision. All of this is directly related to the agility with which organizations are able to change internally in meeting the challenge of the turbulence in their environment.

Because of cultural and technological changes, organizations are required to make internal changes periodically in order to continue to be sustainable. These internal changes are a result of the organization's ability to effectively use their human resource assets which can be inclusive of different generations. The degree to which organizations are successful in these change efforts is in part a function of the degree to which they keep members of different generations in mind and aware of specific required changes and the general need for continual change. Systemic change without considering the culture or the needs of each generation of the workforce in which they are contained is doomed to failure. For this reason, organizational leaders need to understand the needs, desires and work habits of the various generations in the workforce before planning or implementing major changes.

\section{Understanding the Four Generations in the Workforce}

Currently, American corporate leaders in the United States are dealing with a multi-generational workforce as they have four distinct generations working simultaneously (Mujtaba, Hinds and Oskal, 2004). As can be seen from Table 1, the four generations currently in the United States workforce are known as the traditionalists (or veterans), baby boomers, Gen X, and Gen Y individuals. Members of each generation tend to share certain experiences, events and history that help shape their 'generational personality' during their socialization in the society.

Table 1 - Various Generations in the United States

\begin{tabular}{|c|c|c|c|}
\hline $\begin{array}{l}\text { Generation } \\
\text { Category }\end{array}$ & Birth Years & $\begin{array}{l}\text { Population in } \\
\text { the USA }\end{array}$ & Common Characteristics \\
\hline Traditionalists & 1900 s-1945 & 75 million & Stability and security \\
\hline Baby Boomers & $1946-1964$ & 80 million & Teamwork and human rights \\
\hline Generation $X$ & $1965-1976$ & 46 million & Empowerment and social responsibility \\
\hline Generation $Y$ & $1977-1994$ & 70 million & Technology and personal growth \\
\hline Cyberspace Gen. & $1995-$ Present & 20 million & Globalization and internet \\
\hline Total & & 290 million & \\
\hline
\end{tabular}


The characteristics discussed are generalities and they do not necessarily all apply to each person and some of the characteristics described for one generation may very well apply to individuals of other generations as well. However, the characteristics described are likely to apply more often to individuals of the specified generation. As such, managers must be cautious and not stereotype specific individuals when it comes to hiring and evaluation solely based on these categories since each person is unique and may not necessarily fit the mold for the specified generation based on his or her place of birth. Nonetheless, understanding the various generational personalities can help managers and leaders build bridges in the work environment to create collaborative teams in today's learning organizations. Furthermore, this understanding may assist them to effectively recruit and retain diverse individuals by meeting the majority of their intrinsic needs in order to keep them loyal and committed to the organization. As one reads about the different generations, it is best to look for potential implications on one's own organizational systems and environments. As learning and wisdom increases, one can then appropriately use human systems (on an individual and organizational basis) to gain a true competitive advantage in the twenty first century work environment. Current leaders, like past leaders, can reap bottom-line benefits from using 'big picture' systems thinking to create user friendly cultures that accommodate the needs of a diverse generation of workers (Lancaster et al, 2002). According to Lancaster et al (2002), with the existence of four diverse generations of employees in the work system, misunderstandings might become a common everyday occurrence if teamwork and team learning is not encouraged. When generational collisions occur in the workplace, the results can reduce profitability, present hiring challenges, increase turnover rates, and decrease morale among all generations of employees in the department. Understanding the various generational personalities is essential in building bridges and creating new learning and development opportunities in the work environment. The four generations are identified below and since each generation is somewhat different, note the various suggested rewards and retention methods.

Traditionalists (veterans) were born between the turn of the last century and the end of World War II (1900-1945) and they make up about 75 million individuals in the United States. Traditionalists, because of their experience, have learned to do without much participation, and the management style they learned came from the military (Lancaster et al, 2002). They were cautious, did not take much risk, spoke only when spoken to, and have been obedient to societal rules. They expect career security of lifelong employment and do not appreciate job-hopping or downsizing jobs. Currently, there are many Traditionalists working in large numbers at fast food locations and retail outlets such as various department stores, McDonalds, Wal-Mart, Home Depot, and many top Fortune 500 organizations. This generation prefers a learning environment that offers predictability, stability, and security.

The baby boomers were born around 1946-1964 and make about 80 million individuals in the United States (Lancaster et al, 2002). They grew up in suburbs, had educational opportunities above their parents, saw lots of consumer products hit the marketplace (calculators, appliances) and the television had a significant impact on their views of the world regarding equal opportunity and other human rights. Many members of this generation served in the military throughout the United States and around the globe. They enjoy perks that allow them to have more free time like errand-running service, car washes, food service, etc. The preferred learning environment of the Boomers is interactive and team activities.

Generation X, making up about 46 million individuals in the United States, born around 1965 through 1976, transitioned into work environment during the 1990s. They had plenty of choices in choosing their professions and jobs (Lancaster et al, 2002). The technological advancements exacerbated their successors as they are techno savvy unlike some of their Boomer competitors. Rather than 'paying their dues for a number of years' as previous generations did, they were able to demand that organizations adapt to their way of doing things, creating disbelief from the previous generations. This generation was raised in the fast lane with one or both parents working. They detest micro-management in the work 
environment and want constant feedback on how they are performing. They are the job-hopping generation and are attracted to work projects instead of jobs. They are making a difference in society by expecting firms to be socially responsible (i.e. Green peace, recycling, bettering the environment). For this group, freedom and autonomy are considered the ultimate rewards as this generation grew up being independent (Mujtaba \& Karadayi, 2004). This generation believes as long as the job gets done, it is not important where or when it occurs. They have been raised in 'fun environments' and like for their training to be fun and interactive with immediate feedback.

Generation $Y$ individuals, mostly born between 1977-1994, make up about 70 million individuals (Mujtaba \& Karadayi, 2004) who are techno-savvy, multi-tasking and have had access to cell phones, personal pagers, computers, and concern for personal safety most of their lives. It is predicted that this generation will be more loyal than the Gen Xers provided they are stimulated and have learning opportunities. They are likely to challenge 'why' systems function the way they do and how things operate, and futurists feel this generation will make the greatest contributions (Lancaster et al, 2002). According to Eisner (2004) and Spence (2001), Gen Y individuals will be more likely to deal with finding facts quickly and to find more of such data as they will have a short "shelf life." So, today's college age students must learn to think on their feet, make decisions based on new knowledge, create new knowledge through inductive and deductive reasoning, experience different methods and cultures, and learn faster than their previous generations because information is changing faster than ever and continuous learning is becoming the norm. The global world of training and education will spend about $\$ 2$ trillion annually and around $\$ 740$ billion just in the United States (Eisner, 2004) to make sure their employees are well educated, flexible and are able to think at a fast pace while adjusting to the changing needs of their clients. So, in terms of learning style, Generation Y, students expect education to be about application and doing of things that relate to their current interests. Also, they learn best when the learning process and facilitation involves them in a fun and humorous manner. This generation strongly resists the traditional style of lecturing by academicians and "know-it-all" experts since they prefer to be involved in the process. As a matter of fact, Spence (2001) mentioned that Gen Y students are likely to "treat traditional assignments like the throwaway instructions you get with a new computer.” Perhaps, this mindset is why the formats of case analysis, debates, teamwork, presentations, and jointly working on real world exercises seem to be most suitable and more enjoyable in many of today's educational settings.

\section{Understanding Generation X Population}

The Generation $X$ population has had plenty of choices in choosing their professions and jobs in their entry to the workforce. Kupperschmidt (2000) summarized the typical characteristics of GenX employees as follows: They are self-reliant, they want a balance, they do not like to commit, they are skeptical, and they embrace diversity in the culture. GenX employees have been labeled as slackers who lack strong work ethics since many are supposedly focused on their wants and needs (Harken, 2000). The have also been described as job hoppers who are rebellious, workers changing jobs about every 3 years (Cordeniz, 2002). According to Rodriguez et al (2003), a survey found that 55\% of one organization's employees had planned or had the thought of leaving before hitting the three-year mark with the organization. GenX employees are said to be the "work to live" generation, whereas the baby boomers are considered to be the "live to work" population (Rodriguez et al, 2003).

Researchers and workforce leaders know that the baby boomers are on their way to retirement and the workforce shortage will become tighter. As such, recruiting and retaining qualified workers becomes an important aspect of any large organization's task. Harken (2000) said that GenX prefers "naked management," which requires managers and leader to create a positive work culture where a trusting and genuine relationship can be built with GenX employees. According to Harken (2000), the 
components of the naked model are freedom, interaction and involvement, recognition, empathy strengthening the working relationship between managers and GenX workers, and effective communication on a regular basis. Tulgan (1996), a researcher on this generation, interviewed 85 diverse groups of GenX individuals by asking them "how are you being managed and how is that management style affecting your work?” Majority of the responses found that they are not motivated by long term rewards or the use of fear. Furthermore, GenX workers do not want to be micromanaged and don't want managers to waste their time with lectures and boring meetings. Tulgan (1996) summarized the GenX expectations into various categories as this generation of workers expect managers to:

1. Invest in their employees.

2. Be able and willing to provide effective feedback.

3. Understand work issues and be able to respond to their needs and concerns (in other words they do not like being ignored). And

4. Possess and have the power to access information and resources.

Some researchers claim that the GenX employees have a lower expectation of what institutions and society have to offer them (O’Neill, 2002). One reason for understanding the expectations of workers is to effectively maximize recruiting and retention efforts of qualified employees in the competitive economic times. As such, this generation of employees expects some leeway and control over work environment, reward and recognitions, and interaction with managers. Overall, one can summarize that GenX employees do not care much about long-term loyalty because they want to be regarded as free agents. They prefer being trained, developed and ready for more responsibilities and opportunities. At the mean time, they want flexibility and choose jobs that offer them most immediate joy and exploration of opportunities.

\section{Understanding Generation $Y$ Workers}

In the Generation Y (Gen Y) segment of the American market, consumers have needs and preferences that are very different than any other generation due to their upbringing and socialization factors. Organizational leaders must pay attention to Gen Y-ers as they make up about 70 million Americans born from 1977 through 1994. Their shared experiences have included invasion of Iraq, the removal of Taliban in Afghanistan, the attacks on New York's Twin Towers during September $11^{\text {th }} 2001$, the widespread profiling of individuals associated with terrorism, the impeachment trials of President Clinton over sex allegation statements, the Columbine high school shootings, several cult members of different groups committing suicide, the fuss over the Y2K challenges which did not cause the expected problems, the wave of electronic shopping/banking, and the Dot.Com bust among many others (Mujtaba \& Karadayi, 2004). They also seem to prefer video games, internet and DVD compared to mass media television and movies.

Generation Y individuals are more technologically savvy and more interactive than any other generation prior to them. It is estimated that those who are currently between the ages of 18-24 years of age tend to spend about ten hours online each week while watching television about ten hours as well. Jason Ritter, a television actor, falls in this age category and, during an interview on October $15^{\text {th }} 2004$ with the hosts of "The View" on the American Broadcasting Corporation (ABC), admitted that he is hooked on video games. Jason, son of the late actor John Ritter, mentioned how he is actually addicted to video games since he often plays by himself while ignoring friends, family members and other important chores. He mentioned that he knows he is addicted to video games because he read that these are the same exact symptoms shown by those who are addicted to alcohol. So, some Generation Y members tend to heavily engage in video games and instant messaging through their computers while listening to the latest diverse music online. Researchers conclude that organizations can best reach this group via word-of- 
mouth advertisement which can reach millions of individuals instantly through the connectivity of technology savvy individuals. Generation Y-ers tend not to take too much risk as they have seen the Dot.Com bust and the downfall of large organizations such Enron and WorldCom where people either invested heavily in them for quick returns or their leaders lied to their stakeholders. They also distrust the media because they know politicians and governments tend to use media to sway perceptions. They feel as though they are living in a very uncertain world where much animosity exists between individuals in different countries due to their personal beliefs which may be very different than that of Americans. A good percentage of the Generation Y-ers are worried about crimes, wars, and terrorism attacks. Research has shown that while concerns about possible terrorist attacks on the United States either were reduced or stayed the same for many individuals, Generation Y individuals' level of concern about such attacks actually increased from 51\% in 2002 to 61\% in the year 2003 (Mujtaba \& Karadayi, 2004). This two digit or eleven percentage increase in the level of concern could be due to the widespread mistrust of the American government, by outsiders, which is seen as an imperialist trying to exercise aspects of colonialism in developing countries.

Generation Y individuals tend to be open to diversity of ideas, cultures, music, and points of views. They are able to adapt quickly to new lifestyles and cultures compared to their parents. They are not hard core "my way or the highway" or dichotomous individuals as they believe in contrasting points of views. Their values include diversity, dignity, fairness, and equality for people in all respects. They also like to challenge the status quo and extreme paradigms as they want proof in order to believe and trust others (they may say "Show me the money" as seen in the movie Jerry Maguire with Mr. Tom Cruise as the lead actor). They do not like telemarketers nor do they like those who are involved in hard sell. This generation is best reached by friends, colleagues and technology that is fun, exciting and in touch with their values. They tend to like reality shows because they seem to be more natural than the regular television shows.

Generation Y employees tend to be very interactive and they value learning, flexibility and mutual trust. They follow the rules of their organizations and professions and they tend to be good team players with challenging assignments. They are confident, time-impoverished, can multi-task better than previous generations, and are willing to work hard for good causes. They are also willing to leave organizations for others that are more fair, socially responsive, and loyal to their people. The same is true for their choices in buying products, services and vacations.

This generation has been called the "digital natives" who are connected at all times through their laptops and state of the art wired telephones. They seem to be immersed in a "fun focused" world and heavily involved with fun technology. They value entertainment, humor, fun, excitement, and unique cultural experiences which seem to drive their buying patterns and behaviors. Values theory states that what people value drives their behaviors (Pohlman and Gardiner, 2000) and this is certainly the case with individuals of this generation. They don't watch regular television shows or big Hollywood movies which attracted previous generations in this age group because their values are different. As such, they are considered to be immune to traditional marketing and advertising strategies which organizations use in their conquest for more revenues. Generation Y-ers tend to trust real time information coming from their friends, family members, colleagues, and those in the online community that tend to speak honestly from their hearts about movies, television shows, and best products. They value reality which is why many of them are watching "reality shows" on television. They are the "just-in-time" (JIT) generation of individuals and get information on a JIT basis for product buying choices. They want information that is of use to them in their current situation and lives which is why they rely so much on instant information available on the internet for instant customization. So, "word of mouth" and "story telling" form of advertisement seem to be the best strategy with the Generation Y group of individuals. Overall, with regards to absorbing new information, Generation Y learners expect their education to be about current application and very relevant to their immediate interests. Educators must remember that Gen Y learners 
learn best when the learning is fun and when the facilitation process involves them since the traditional style of lecturing is not their preferred mode of learning.

\section{Making Effective Connections with All Generations}

Lancaster (2002) offers some ideas that organizational systems might use to make generational connections and prevent possible problems. The following are some of Lancaster's suggestions for making effective connections with various generations in the workforce.

1. Organizations should have generational-specific tactics for feedback strategies and to recruit, retain, and train each of the four generations.

2. Recruiting - one-size fits all approach - will not work as we move forward. Two keys here involve knowing the audience the organization wants to attract and understanding their values.

3. An orientation program is a crucial retention tool. This is the first opportunity that an employee can 'connect' to the organization. If the orientation program does not ignite that spark, employees will soon leave. Orientation designers must focus on the history, culture, and mission of the organization.

4. Mentoring programs should link new and experienced workers. Mentoring shortens the learning curve and helps build effective bridges between generations.

5. In a learning organization, information should flow in all directions and every employee should be heard.

6. Benefits, the number of work hours required, places of employment (home/office) have different meanings to the various generations of workers today. Repackaging benefits and allowing benefit package choices are starting to emerge attracting the four generations needed to fill job vacancies.

7. Equalize rewards with each generation by linking rewards to performance.

8. Exit interviews should take place and be documented as they can serve as a feedback loop to gain insight on why specific generations are leaving.

Making connections at the right times with the right individuals and by the right means is a critical element of making any system or culture successful. While it is important to make productive connections with employees and customers of various generations, one must remember that there are other relevant stakeholders impacting the success of each organization as well. Other stakeholders and customers can include the community, unions, suppliers, vendors, etc. that are important part of keeping the system functioning smoothly. Checkland used the acronym "CATWOE" to demonstrate one aspect of systems thinking application (1999, page 18) by pointing out the various elements in the acronym "CATWOE" which stands for customers, actors, transformation, weltanschauung (paradigm or perspective), owners, and environmental constraints. Similarly, Pohlman and Gardiner (2000) provided a decision making framework that considers the values of all stakeholders which are critical to the success of the system in order to maximize the organization's value in the long-term.

\section{Values Driven Behaviors}

A valuable resource for all managers and leaders is the textbook written by Pohlman and Gardiner (2000) which offers a comprehensive introduction to Value Driven Management (VDM) and the holistic approach to decisions. VDM provides a decision-making framework that can be used in a variety of situations with each generation of the workforce. VDM is based upon Values Theory which claims that what people truly value drives their actions and behaviors. The underlying theme is to make decisions that maximize value over time for all relevant stakeholders in the long-term. Value Driven Management is a 
practical model that managers can use in their daily work life in a variety of decision-making scenarios. VDM enlarges upon the concept of value over time and explains that the two key elements of using VDM in decision-making are: one, understanding the values of the organization and its employees; and two, knowing the appropriate time horizon for decision making. The authors explore the underlying assumptions of VDM including (1) what is valued drives action; (2) the creation of knowledge and its appropriate use leads to value creation; (3) there are value adders and value destroyers; (4) values can compete or be complementary; and, last but certainly not least, (5) all employees are employees emphasizing that everyone's input and actions are critically important to the success of the organization!

Pohlman and Gardiner also offer several cases and examples-good and bad, of how companies reveal their values, or relative lack of values, in their decision making. Pohlman makes use of his time as Director of Human Resources at Koch and provides inside information about the philosophy and value system of Koch. One of the best lessons one can learn from his Koch experiences is that developing a value based management system (and/or market-based management at Koch) takes years and top management support. It is not a quick-fix, nor an easily implemented system. VDM is system-wide, an important part of an organization's culture, and as with anything having to do with organizational culture, it takes time and reinforcement to implement. The authors use the Johnson \& Johnson Tylenol case, wellknown to many by now, as an example of how easy it is for a company to make a really good, customerfriendly decision which leads to good will and profit for the company if the values are clear. J \& J's CEO did not have to figure out what to do when Tylenol was tampered with-the ethical value system of J \& J made only one choice possible-pull the product. The resulting benefits to the public and to J\&J as it reaped huge public relations (PR) rewards are well documented. The negative example to this is the Exxon Valdez case. Here, the "too little too late" scenarios, caused an outraged public and billions of dollars in punitive damages. Exxon's CEO didn't seem to have a systematic value system to help him decide how to handle the crisis or the resultant confusion, and then the half-hearted attempt to do "something," caused a PR disaster for Exxon. Similar examples are provided for all the value drivers (the above examples relating to external customer values). Finally, the VDM authors give practical advice on the steps to follow in setting up VDM in any organization. It is not easy nor a panacea. The final section in the VDM textbook integrates the tenets of VDM as it relates to the organization and the individual. The ideal situation, of course, is congruence between organizational values and the employee's values. This leads to inevitable job satisfaction and an environment within which both the organization and the employee can prosper.

The basic purpose of Values Driven Management (VDM) is to motivate managers and employees, when contemplating making decisions or taking actions, to consider the impact of these decisions and actions on the value of the organization over time (Cavico and Mujtaba, 2004). This determination can be accomplished only by an examination of the sets of values held by the relevant constituents (or "stakeholder" groups) of the organization. These encompass world, national, societal cultures and subcultures, organizational culture, the values of employees, suppliers, customers, competitors, and third parties (such as unions and government regulators), and most importantly, but not exclusively, the values of the "owners" of the organization. The subjectivity and diversity of value, the long-term view, and the necessity of foreseeing consequences make VDM decisions quite complex; and thus will require the VDM decision-maker to engage in careful determinations, accurate predictions, equitable balancing and weighing in order to use wise judgment.

There are people, processes, and systems within organizations that add and destroy value. There are, for example, employees within organizations who destroy more value than they create, perhaps as a result of being in the wrong position with the wrong types of skills and abilities, or perhaps they are totally incompatible with their organization's means or ends. It is every employee's responsibility to seek out a role that adds value and ensures success; and the organization's responsibility to eliminate value 
destroyers by placing people in the proper jobs and instituting proper processes and systems. There are eight facets that make up these value drivers.

- Organizational culture. Each organization has its own somewhat unique culture. Anyone within an organization making decisions or taking actions must understand the organizational context within which they must be made.

- Employee's values. Each employee comes to the organization with a set of values. It is essential that the employees' values are congruent with the organization's values. The more the employee's values are congruent with organizational values, the more successful the individual will be and the more successful the organization will be. It is thus crucial for the organization's decision-makers to understand what the organizational culture is, but also to understand what each employee values, and how each can be the most successful in the organization. Each employee, of course, also has the responsibility of finding an organization and role that suits their values, interest, and abilities. When one is considering making a decision or taking an action, therefore, one must think clearly about how this will affect the employees within the organization, how these consequences, in turn, will impact value maximization over time.

- Supplier's values. Attention must be given to the values of the organization's suppliers in order to maximize the organization's value over time. Treating suppliers fairly, creating "partnerships" with suppliers, and acting on their other values will lead to greater value over time, for the suppliers and also the organization.

- Customer's values. Clearly understanding what customer's value, for example, quality of product and service and reliability, and satisfying customers' values are critical to the success of any business. In order to serve customers, the values of the customers and the employees of the organization serving them must be congruent.

- Third party values. Understanding what third parties, such as unions and government regulatory agencies value, such as authority, rules, and compliance, can be very important in making decisions and taking actions within an organization.

- Competitor's values. Competitors' values, such as size and market share, profitability, and image, will drive their strategy, tactics, and actions. Understanding one's competitor's values will lead one to a better understanding of one's competitors; and thus will help one's own organization formulate its strategy.

- Owner values. The owners, the shareholders in a corporate context, have a set of values. They value, for example, a return on assets and equity, sustained growth, a profitable investment, and prestige of the firm. Owner values are the primary focus of VDM, but the other facets cannot be ignored. Of course, when VDM is operational and working well, the values of the owners, the values of the other "stakeholder" groups, and the values of legality and morality will be in harmony.

The VDM model and method is a philosophical as well as a practical approach, which is simple to state and discuss, but laborious to implement. Implementation is difficult because organizations and people are complex, values are diverse and subjective, values of constituent groups are hard to comprehend, and calculating consequences and their long-range impact on value maximization are very challenging tasks. Nonetheless, if VDM is learned well and administered thoughtfully and consistently with today's multi-generational workforce, then the ultimate goals of achieving, creating, and sustaining long-term growth, surplus, wealth, and value maximization can be attained in any national or international organization.

\section{Cultural Variables and Considerations in the International Workforce}

The combination of the eight facets of Value Driven Management and its successful implementation are an appropriate guide for business success in today's multi-generational workforce. 
Conducting business internationally can be more complex than conducting business locally since companies are often dealing with several countries and different cultures. According to Nelson (1999), the climate of international business is created of eight key elements which are relationships, language, religion, values and attributes, laws and the legal government, education, technology, and social organizations. International companies need to ensure that they consider these elements in their decisions along with the implementation of the eight value drivers of VDM in order to make appropriate choices regarding each generation of the workers and customers. Within each culture outside of the United States, there might be different practices and mentalities based on the various generations. In order to be successful in different cultures, international managers have to commit extra time and effort to ensure their business practices are suitable for both the culture and the diverse generations. They need to become fully aware of the foreign culture’s basic mores and norms before starting as managers.

International managers should be cautious and not always follow the culture of their native country; they should try to practice and accommodate the norms and customs of the host country where business is held. According to Mendenhall, Kuhlmann \& Stahl (2001), an effective method for international managers to acquire knowledge regarding foreign culture before starting the managerial position is through spending time in the foreign country while practicing their day-to-day lifestyle. This approach will provide managers the opportunity to understand the local lifestyle, their needs, their desires, and other cultural practices through personal experience as opposed to reading a book. Once managers have adequate knowledge of the local culture, they will be able to work effectively with the various generations of the workforce. Maintaining a relationship with employees is also an essential part of working cooperatively and achieving team success. Periodic evaluation of business practices is a great tool for managers to determine the positives and negatives of their business. This data might allow improvement of business practices, as well as employee satisfaction.

Employee satisfaction and motivation concepts are every important in successful international management. In some cultures rewards and recognition can be appropriate strategies to motivate employees and in other cultures bonuses are the main motivational device. Motivational strategies can differ based on different generations of employees in each culture. Collectivistic countries treasure group accomplishments and individualistic countries value individual achievements. For example, India is a collectivistic country; therefore, Indians may enjoy group success. On the other hand, the United States is an individualistic country; hence, Americans may enjoy individual success. When international managers decide to appreciate their employees' efforts with rewards and recognition; they need to make sure that the appreciation will motivate employees and that they reinforce good performance. For some individuals, such as those who are young and financially unstable, money can be a very effective tool for motivation; therefore, managers need to act accordingly.

The western influence has changed India dramatically in many areas including following the trends established in other countries. Generations $\mathrm{X}$ and $\mathrm{Y}$ in particular seem to follow many western trends that they see in television and on the internet. India's western influence is increasing as international businesses are increasing their presence there in an attempt to capture the market share of nearly one billion prospective consumers. Rapid growth of outsourcing is an example of the international business growth in India. The Indian workforce appreciates appropriate benefits from their employers and these employees of international corporations require various types of benefits suitable to their generation and culture. For example, many of the Indian companies do not offer appropriate medical insurance and workers' compensation to their employees. Therefore, providing adequate medical insurance and workers' compensation might attract potential employees while motivating current employees. International managers should always ensure the safety of their subsidiaries in foreign nations to prevent disasters like the Bhopal tragedy. The Bhopal tragedy occurred on December $3^{\text {rd }}$, 1984 at a chemical plant called Union Carbide in Bhopal, India. Union Carbide, India was a subsidiary of an American company. The disaster killed and injured thousands of people and such tragedies are disliked by all generations. The 
disaster mainly occurred due to insufficient safety mechanisms in the company. Even though it was reported that all of the deficiencies were corrected; it was not enough to prevent the disaster from happening (Cavico \& Mujtaba, 2004). Managers need to ensure that employees of subsidiaries are treated the same as employees in the parent company. If disasters like the Bhopal tragedy occur, then not only will employees mistrust their managers but companies will also lose a vast amount of money since they will have to compensate all the victims.

Corporate training programs are one of the main methods to bring international employees together to share knowledge and best practices, and to gain the requisite knowledge regarding the company. In training programs, it is beneficial for employees from all generations to attend and voice their concerns. This will provide an opportunity for employees and employers to understand each other regardless of cultural and generational differences. Ethical training programs, in the international environment, are another excellent avenue to ensure people are treated fairly and many companies offer such interaction opportunities and workshops in order to hear the concerns of the local people. According to Mitchell (2003), "The aim of an ethics training program is to reinforce existing personal values and tie them into 'the big picture' values of the company." Effective ethics training programs will allow employer and employees to understand various ethical standards. When companies conduct ethical training programs, they need to ensure that the content of the training is appropriate for a specific culture as well as for other cultures (Mitchell, 2003). Basically, managers should act according to the norms and customs of the country and local culture in order to win the hearts and minds of its citizens regardless of their generational differences.

\section{Summary}

Decision-making with regard to dealing with employees is one of the critical tasks in business; therefore, managers need to ensure that their decisions are appropriate for the business while considering the personal interests and desires of each person. Organizational learning is an appropriate method for employees to expand their knowledge regarding the organization, and teamwork is an excellent method for employees to work together effectively. Due to late retirements and early employment, the number of different generations in the workforce is increasing and it is important that managers understand the various generations' desires in order to effectively work with them as a team. This understanding can further help them target their recruitment efforts to each segment of the workforce in order to have a diverse pool of qualified applicants for job postings. The knowledge about the various generations can also assist managers to be effective coaches and mentors to new employees and "rising stars" as they make their way up the leadership ladder in the organization. Values Driven Management is one application of the system thinking paradigm where decisions are analyzed in terms of its total impact from a holistic approach. Understanding systems and applying systems thinking in a format such as the VDM concept is a critical leadership and organizational skill necessary in the $21^{\text {st }}$ century's multi-generational workforce. As the environment becomes increasingly complex, and as organizational leaders search for means to deal with this complexity, it will become natural for them to turn to the foundations and practices of systems theory, to see the impact of each generation on the success of the firm, in order to effectively maneuver through this changing landscape. In the $21^{\text {st }}$ century, international business is dramatically increasing; therefore, the corporate world has more international managers than previous years. International managers should not practice ethnocentricity (imposing one's cultural values on others) but rather they should attempt to consider their actions with regard to the local customs and practices. Managers should work and use appropriate practices based on the culture of the country where the business is being conducted. Dealing with various cultures and generations is a critical task for twenty first century managers of learning organizations. Therefore, managers should have the requisite knowledge of various cultures in their workforce along with an understanding of the desires of various 
generations to be successful as leaders both with employees and consumers. Furthermore, academic and corporate educators should appropriately inform and equip their learners about the differences in the workforce and consumer populations so they can make the right decisions while functioning effectively in the context of generational and cultural differences in the twenty first century organization.

\section{Bibliography}

- Capra, F. (1996/7). The web of life. New York: Doubleday.

- Gazzaniga, M. S. (1998). The mind's past (1st ed.). Los Angeles: University of California Press.

- Cavico, F. \& Mujtaba, B., (October 2005). Business Ethics: Transcending Requirements through Moral Leadership. Pearson Custom Publications. U.S.A. ISBN: 0-536-85783-0. Address: 75 Arlington Street. Suite 300. Boston Mass, 02116. Phone: (800) 374-1200. Or: (800) 922-0579.

- Checkland, P. \& Scholes, J. (1999). Soft systems methodology in action. New York: Wiley.

- Checkland, P. (1999). Systems Thinking, Systems Practice: A 30-Year Retrospective. New York, NY: John Wiley \& Sons, Inc.

- Collins. J.C. (2001). Good to great: Why some companies make the leap...and others don't. New York: Harper Collins.

- Cordeniz, Judy, A. (2002). Recruitment, retention, and management of Generation X: Focus on nursing professionals. Journal of Healthcare Management. 47 (4): 237.

- Eisner, Susan P., (2004, September). Teaching Generation Y College Students: Three Initiatives. Journal of College Teaching and Learning, Volume 1, Number 9. Pages 69-84. ISSN: 15440389.

- Harken, Gayla. (2000). Naked Management: Bare Essentials for Motivating the X-Generation at work. Psychiatric Rehabilitation Journal. 23 (4): 410.

- Jones, Gareth R., George, Jennifer M. (2003). Contemporary Management. Third edition. New York, NY: McGraw-Hill.

- Kupperschmidt, Betty, R. (2000). Tips to help your recruit, manage, and keep generation $X$ employees. Nursing Management 31 (3): 58.

- Lancaster, L., Stillman, D., \& MacKay, H. (2002). When generations collide. New York: HarperCollins

- Mitchell, C. (2003). A short course in International Business Ethics: Combining Ethics and Profits in Global Business. World Trade Press: Professional Books for International Trade. Pages $110-122$.

- Mujtaba, B.; Hinds, R. M..; \& Oskal, C. (December 2004). Cultural Paradigms of Age Discrimination and Unearned Privileges. Journal of Business and Economic Research, Volume 2, Number 12.

- Mujtaba, B. \& Karadayi, S. (June 2004). "Entering the Tourism Industry and Generation Y "Prospects:" Turkish Entrepreneurs Planning to Enter the American Market." International Business and Economics Research Journal. Volume 04, Number 02. Western Academic Press.

- Mujtaba, B. \& Mujtaba, L. (2004). "Creating a Healthy Learning Environment for Student Success in the Classroom." The Internet TESL Journal. Vol. X, No. 2, February 2004. The article can be retrieved via the following URL link: http://iteslj.org/ or: http://iteslj.org/Articles/Mujtaba-Environment.html.

- Munchnick, M. (1996). Naked Management: Bare Essentials for Motivating the X-generation at work. Delray Beach, Florida: St Lucie Press.

- Nelson, C.A. (1999). International Business: A Manager's Guide to Strategy in the Age of Globalism. International Thomson Business Press. Pages: 72-74. 
- O’Neill, Edward. (2002). Shaping America's health care professions: How the health sector will respond to "generation X”. Western Journal of Medicine. 176 (2): 139.

- Pohlman, R. \& Gardiner, G. (2000). Value Driven Management: How to Create and Maximize Value Over Time for Organizational Success. New York: AMACOM.

- $\quad$ Reichheld, F.F. (1996). The Loyalty Effect, Mass: Harvard Business School Press.

- Rodriguez, R.O., Green, M. T., Ree, M.J. (2003). Leading Generation X: Do the old rules apply? Journal of Leadership \& Organizational Studies. 9 (4): 67.

- Scholtes, P.R., (1998). The leader's handbook. New York: McGraw Hill.

- Senge (1994). The Fifth Discipline Fieldbook: Strategies and tools for building and learning. New York, NY: Doubleday.

- Senge, P. M. (1990). The Fifth Discipline: The Art and Practice of the Learning Organization. New York, NY: Currency/DoubleDay.

- Senge, Peter (1992). Learning Organizations and Human Resources. American Society for Training and Development (ASTD) National Conference. New Orleans.

- Spence, L. d. (2001, Nobember). The Case Against Teaching. Change 33 (6), 10 (10). Retrieved October $25^{\text {th }} 2004$ from EBSCO Database.

- The View, 2004. Interview with Jason Ritter. Show on American Broadcasting Corporation (ABC) aired on October $15^{\text {th }} 2004$ at 11:00-12:00 AM, EST.

- Tulgan, B. (1996). Correcting the "slacker myth" - managing generation $X$ in the workplace. Manage, 48, 14-16.

- Von Bertalanffy, L. (1969). General system theory: foundations, development, applications. New York: Gordon and Breach Science Publishers. 
Notes 